\title{
Kajian Kuat Tekan Beton HVFA Kadar 60\% Memadat Sendiri Terhadap Beton Normal Dengan Kekangan Teflon-Grease
}

\author{
Silvia Sabela Andrianing ${ }^{[1]}$, Agus Setiya Budi ${ }^{[2]}$, Stefanus Adi Kristiawan ${ }^{[3]}$ \\ [1]Mahasiswa Program Studi Teknik Sipil Fakultas Teknik Universitas Sebelas Maret \\ [2],[3]Pengajar Program Studi Teknik Sipil Fakultas Teknik Universitas Sebelas Maret \\ Jl. Ir. Sutami 36 A, Kentingan Surakarta 57126. Telp (0271)647069. Fax 662118 \\ Email : silviasabella6@gmail.com
}

\begin{abstract}
Increased cement production contributes to $\mathrm{CO}^{2}$ pollution. Therefore, research is needed to examine other materials which are substitutes for cement that are more environmentally friendly, one of the potential substances is fly ash. Fly ash is a coal combustion waste containing $80 \%$ silica and alumina and is pozzolanic. As a substituent of cement, the use of high levels of fly ash (> 50\%) is called High Volume Fly Ash Concrete (HVFAC). In this research, we will study the effect of $60 \%$ fly ash on HVFA-SCC on the characteristics of the concrete produced. In testing, teflon and grease restraints intending to reduce friction that occurs between the test machine plate and the surface of the test object. The method used in this study is the experimental method. The sample used is 60\% HVFA-SCC and normal concrete as a comparison. Cylinder specimens with a size of $150 \mathrm{~mm} \times 300 \mathrm{~mm}$. The results showed that the compressive strength of HVFA-SCC 60\% were still smaller than normal concrete. The average compressive strength of HVFA-SCC is $21.871 \mathrm{Mpa}$ while normal concrete is $24.070 \mathrm{Mpa}$. The addition of Teflon restraint and grease produces a uniform collapse on the test object.
\end{abstract}

Keywords: fly ash, HVFA-SCC, teflon and grease

\begin{abstract}
Abstrak
Produksi semen yang semakin meningkat turut berkontribusi dalam pencemaran $\mathrm{CO}^{2}$. Oleh karena itu perlu ada kajian untuk meneliti bahan lain pengganti semen yang lebih ramah lingkungan, salah satu bahan yang berpotensi adalah fly ash. Fly ash adalah limbah pembakaran batu bara yang mengandung silica dan alumina mencapai $80 \%$ dan bersifat pozzolan. Sebagai subituen semen, penggunaan fly ash dengan kadar tinggi (>50\%) disebut dengan High Volume Fly Ash Concrete (HVFAC). Pada penelitian ini akan dikaji tentang pengaruh kadar fly ash $60 \%$ pada beton HVFA-SCC terhadap karakteristik beton yang dihasilkan. Pada pegujian ditambahkan kekangan teflon dan grease dengan tujuan untuk mereduksi friksi yang terjadi antara plat mesin uji dengan permukaan benda uji. Metode yang dipakai dalam penelitian ini adalah metode eksperimen. Sampel yang digunakan adalah HVFA-SCC kadar 60\% dan beton normal sebagai pembanding. Benda uji berbentuk silinder dengan ukuran $150 \mathrm{~mm}$ x $300 \mathrm{~mm}$. Hasil penelitian menunjukkan bahwa nilai kuat tekan HVFA-SCC 60\% masih lebih kecil dibandingkan dengan beton normal. Rata-rata kuat tekan HVFA-SCC 60\% sebesar 21,871 Mpa sedangkan beton normal sebesar 24,070 Mpa. Penambahan restraint teflon dan grease menghasilkan keruntuhan yang merata pada benda uji.
\end{abstract}

Kata Kunci : fly ash, HVFA-SCC, teflon dan grease

\section{PENDAHULUAN}

Semakin rumit desain konstruksi dan kebutuhan akan tulangan yang semakin rapat untuk mendapatkan kekuatan tarik, beton yang dapat mengalir sendiri (self compacting concrete atau SCC) sangat cocok diterapkan. Dengan memiliki sifat workability yang tinggi dan memanfaatkan berat sendiri, self compacting concrete (SCC) dapat lebih mudah mengisi kedalam rongga-rongga antar tulangan. Diantara semua kelebihan self compacting concrete (SCC) tersebut terdapat dampak negatif bagi lingkungan. Self compacting concrete (SCC) membutuhkan proporsi semen yang lebih banyak dibandingkan dengan beton konvensional. Produksi semen sendiri berkonstribusi menghasilkan emisi gas CO2. Fly ash merupakan salah satu bahan yang sering digunakan sebagai pengganti semen. Fly ash adalah limbah pembakaran batu bara yang mengandung silica dan alumina mencapai 80\% dan bersifat pozzolan. Beton HVFASCC memiliki sifat lebih liat atau nilai daktilitasnya lebih tinggi dibandingkan beton normal dan sebaran energinya lebih merata dilihat dari nilai index toughness yang dihasilkan (Karina, 2018).

Pengujian kuat desak beton silinder dengan menggunakan alat Unit Testing Machine (UTM) yang dilakukan biasanya terjadi tambahan gaya friksi pada ujung atas dan bawah benda uji. Jika dilakukan penguranagn gaya friksi pada ujung benda uji mengakibatkan grafik yang dihasilkan pada daerah descending branch lebih curam, sehingga dapat dikatakan hal tersebut sangat berpengaruh pada grafik tegangan-regangan yang dihasilkan. Untuk dapat mengetahui perilaku tegangan-regangan beton secara murni, perlu dilakukan upaya untuk meredam gaya friksi tersebut. Salah satu cara yang dapat dilakukan adalah menambahkan media pereduksi gaya friksi pada ujung atas dan bawah benda uji. 


\section{DASAR TEORI \\ HVFA-SCC}

Fly ash adalah produk sampingan terutama dari pembangkit listrik tenaga batubara merupakan partikel yang sangat halus dengan diameter antara 1 - 150 mikron meter dan berbentuk butiran bulat (Mochamad Solikin, 2012). Butiran fly ash akan mengisi rongga-rongga antar agregat sehingga berperan sebagai filler, fly ash juga berperan menambah kemampuan beton untuk mengalir walaupun dengan faktor air semen yang kecil. Kandungan silica pada fly ash akan mengikat $\mathrm{Ca}(\mathrm{OH})_{2}$ untuk menghasilkan $\mathrm{CSH}$ (Calsium Silicat Hydrate) yang merupakan senyawa pembangun kekuatan beton. $\mathrm{Ca}(\mathrm{OH})_{2}$ adalah produksi hidrasi reaksi dari semen dengan air memiliki sifat rapuh dan larut dalam air, sehingga kehadiran fly ash bermanfaat untuk meningkatkan durabilitas beton (Galang,2017).

HVFA-SCC adalah perpaduan antara HVFAC dan SCC dimana pembuatan beton dibuat dengan kadar fly ash minimal 50\% dari binder dan memiliki sifat-sifat beton segar sama seperti SCC biasa. Penggunaan fly ash dimaksudkan untuk meningkatkan workability beton segar dan juga mengisi rongga-rongga yang ada pada beton. HVFA-SCC dapat mengalir dan memadat dengan memanfaatkan berat sendiri, sehingga tidak diperlukan proses pemadatan dengan menggunakan alat.

\section{Mix Design}

Mix design dalam pembuatan SCC diperlukan trial komposisi bahan penyusunnya. Untuk menyusun komposisi tersebut ada aturan-aturan pula yang perlu diterapkan agar kriteria flowability dan resistensi terhadap segregasi dapat dicapai. Berdasar The European Guidelines for Self-Compacting Concrete (2002) merekomendasikan range komposisi permeter kubiknya sebagai berikut :

1. Agregat kasar $\leq 50 \%$ dari berat total agregat

2. Rasio air/powder dari volume adalah 0,8-1,1

3. Total powder (semen $+f l y$ ash) adalah $400-600 \mathrm{~kg} / \mathrm{m}^{3}$

4. Agregat halus $>40 \%$ dari volume mortar

5. Agregat halus $>50 \%$ dari total berat agregat

6. Air $<200 \mathrm{lt} / \mathrm{m}^{3}$

7. Pasta $>40 \%$ dari volume campuran

\section{Kekangan pada Pengujian Beban Uniaksial Beton}

Perilaku beton dibawah tekanan uniaksial biasanya diperoleh dengan pengujian beton silinder pada laju perpindahan konstan, dimana beban uniaxsial yang diterapkan didistribusikan memeluai plat baja seperti yang ditunjukan pada Gambar (a).

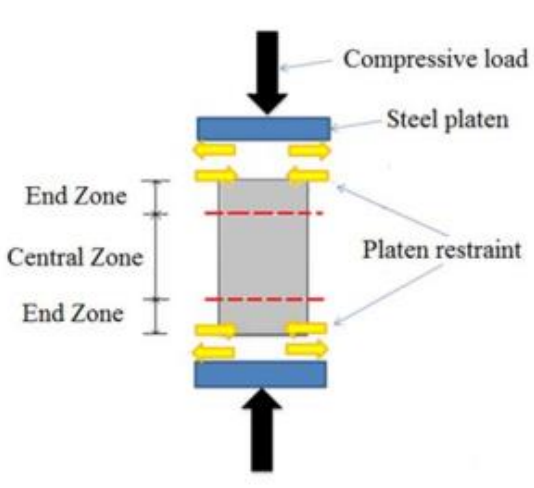

(a)

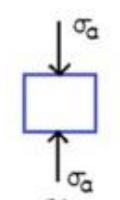

(b)

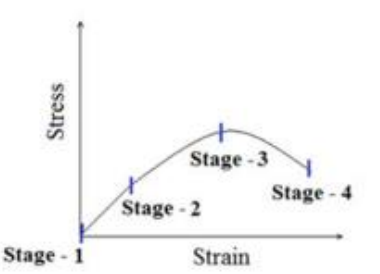

(d)

Gambar 1 (a)ilustrasi uji beban uniaxial pada silinder beton (b) tekanan elemen di zona tengah (c) tekanan elemen pada zona ujung (d) perilaku tekanan-regangan beton (S. Kumar, 2016).

Zona tengah silinder mengalami tekanan uniaksial yang hampir seragam digambarkan pada Gambar (b), sementara keadaan kompleks terjadi seperti Gambar (c) pada zona ujung karena pengaruh gesekan antara spesimen dan pelat baja, yaitu keadaan pengekangan ujung spesimen. Jika pengekangan plat dikurangi dari kedua ujung spesimen $\sigma \mathrm{c}$ akan mendekati nol di zona pusat. Sehingga jika hambatan gesek berkurang ketinggian zona pusat akan meningkat, menghasilkan keruntuhan yang lebih cepat setelah mencapai kekuatan tertinggi. Oleh karena itu, sangat penting untuk meminimalkan efeknya untuk memahami perilaku beton dibawah kompresi murni.

\section{METODE PENELITIAN}


Metode penelitian yang digunakan adalah eksperimental yang dilakukan di Laboratorium Struktur dan Laboratorium Teknik Mesin Fakultas Teknik Universitas Sebelas Maret Surakarta. Benda uji yang digunakan berbentuk silinder dengan ukuran $15 \mathrm{~cm}$ x $30 \mathrm{~cm}$. Sampel terdiri dari 5 sampel HVFA-SCC 60\% dan 3 sampel beton normal. Pengujian yang dilakukan adalah pengujian kuat desak menggunakan UTM (Universal Testing Machine). Kemaudian data yang didapat diolah menggunakan Microsoft Excel.

\section{HASIL DAN PEMBAHASAN}

\section{Hasil Pengujian Material}

Pengujian material yang dilakukan meliputi pengujian agregat kasar dan agregat halus sesuai standart ASTM. Pengujian agregat tersebut dilakukan di Laboratorium Bahan Fakultas Teknik UNS Surakarta. Pada agregat kasar dilakukan pengujian spesific gravity (SNI-1969-2008) dan abrasi (SNI-2417-2008). Pada agregat halus pengujian yang dilakukan adalah kandungan lumpur, kandungan zat organik, dan pengujian spesific gravity (SNI 1970 2008). Selain itu juga dilakukan pengujian material fly ash dilakukan oleh Laboratorium MIPA Terpadu Universitas Sebelas Maret.

Tabel 1. Hasil Pengujian Agregat Kasar

\begin{tabular}{lccc}
\hline \multicolumn{1}{c}{ Pengujian } & Hasil & Strandart & Kesimpulan \\
\hline Absorbtion & $2.1 \%$ & - & - \\
\hline Apparent Spesific Gravity & $2.6478 \mathrm{gr} / \mathrm{cm}^{3}$ & - & - \\
\hline Bulk Spesific Gravity & $2.5084 \mathrm{gr} / \mathrm{cm}^{3}$ & - & - \\
\hline Bulk Spesific SSD & $2.5610 \mathrm{gr} / \mathrm{cm}^{3}$ & $2.5-2.7 \mathrm{gr} / \mathrm{cm}^{3}$ & Memenuhi \\
\hline Abrasi & $26.92 \%$ & $<50 \%$ & Memenuhi \\
\hline
\end{tabular}

Tabel 2. Hasil Pengujian Agregat Halus

\begin{tabular}{lccc}
\hline \multicolumn{1}{c}{ Pengujian } & Hasil & Standart & Kesimpulan \\
\hline Absorbtion & $1.93 \%$ & - & - \\
\hline Apparent Specific Gravity & $2.627 \mathrm{gr} / \mathrm{cm} 3$ & - & - \\
\hline Bulk Specific Gravity & $2.5 \mathrm{gr} / \mathrm{cm} 3$ & - & - \\
\hline Kandungan Zat Organik & Kuning Muda & Kuning Muda & Memenuhi syarat \\
\hline Kandungan Lumpur & $4.5 \%$ & Maksimal $5 \%$ & Memenuhi syarat \\
\hline Bulk Specific SSD & $2.548 \mathrm{gr} / \mathrm{cm} 3$ & $2.5-2.7 \mathrm{gr} / \mathrm{cm} 3$ & Memenuhi syarat \\
\hline
\end{tabular}

Material fly ash dilakukan pengujian XRF (X-Ray Fluorescence) didapatkan hasil sebagai berikut:

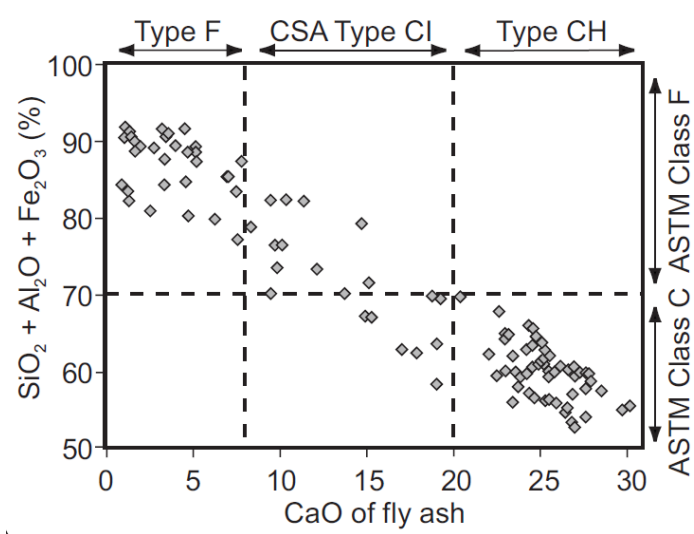

Gambar 2. Klasifikasi Fly Ash Berdasarkan Hubungan Presentase $\mathrm{CaO}$ dan $\mathrm{Al}_{2} \mathrm{O}_{3}+\mathrm{SiO}_{2}+\mathrm{Fe}_{2} \mathrm{O}_{3}$

Jumlah kandungan $\mathrm{Al}_{2} \mathrm{O}_{3}+\mathrm{SiO}_{2}+\mathrm{Fe}_{2} \mathrm{O}_{3}$ adalah sebesar 64,17\% dengan kandungan $\mathrm{Al}_{2} \mathrm{O}_{3}$ sebesar 11,29\%, $\mathrm{SiO}_{2}$ sebesar 31,76 \%, $\mathrm{Fe}_{2} \mathrm{O}_{3}$ sebesar 21,12\%. Sedangkan kadar $\mathrm{SO}_{3}$ sebesar 1,67\% dan $\mathrm{CaO}$ sebesar 15,02\%. Sehingga menurut ASTM C-618 fly ash yang digunakan termasuk kedalam fly ash kelas C sedangkan menurut CSA A3001 termasuk fly ash tipe $\mathrm{Cl}$.

\section{Mix Design}

Perencanaan mix design didasarkan SNI-03-2384-2000 dan menyesuaikan EFNARC 2002 untuk ketentuanketentuan SCC. Setelah mix design dibuat dilakukan beberapa kali trial. Penghitungan secara lengkap rancang cam- 
pur adukan beton atau mix design disajikan pada lampiran. Dari penghitungan tersebut diperoleh kebutuhan bahan adukan beton jenis High Volume Fly Ash - Self Compacting Concrete (HVFA-SCC) dan jenis Beton Normal untuk $1 \mathrm{~m}^{3}$ adalah sebagai berikut :

Tabel 3. Rancang Campur Beton High Volume Fly Ash - Self Compacting Concrete (HVFA-SCC) dan Beton Normal

\begin{tabular}{cccccccc}
\hline Kode & $\begin{array}{c}\text { Presentase } \\
\text { Fly Ash }\end{array}$ & $\begin{array}{c}\text { Semen } \\
\left.\mathbf{( k g} / \mathbf{m}^{3}\right)\end{array}$ & $\begin{array}{c}\text { Fly Ash } \\
\left.\mathbf{( k g} / \mathbf{m}^{3}\right)\end{array}$ & $\begin{array}{c}\text { Kerikil } \\
\left.\mathbf{( k g} / \mathbf{m}^{3}\right)\end{array}$ & $\begin{array}{c}\text { Pasir } \\
\left.\mathbf{( k g} / \mathbf{m}^{3}\right)\end{array}$ & $\begin{array}{c}\text { Air } \\
\left.\mathbf{( 1 t} / \mathbf{m}^{3}\right)\end{array}$ & $\begin{array}{c}\text { SP } \\
\left(\mathbf{l t} / \mathbf{m}^{3}\right)\end{array}$ \\
\hline HVFA 60\% & $60 \%$ & 200 & 300 & 771.32 & 867.62 & 145 & 8 \\
NC & - & 450 & 0 & 954.69 & 670.31 & 225 & 0 \\
\hline
\end{tabular}

\section{Hasil Pengujian Beton Segar}

Pengujian High Volume Fly Ash - Self Compacting Concrete (HVFA-SCC) terdiri dari Flow Table Test. L-Box Test. dan $V$-funnel Test dengan ketentuan berdasarkan EFNARC 2002. Pada beton normal dilakukan pengujian slump.

Tabel 4. Hasil Pengujian Beton Segar HVFA-SCC

\begin{tabular}{lccc}
\hline \multicolumn{1}{c}{ Pengujian } & Hasil & Syarat & Kesimpulan \\
\hline Slump flow & $700 \mathrm{~mm}$ & $650-800 \mathrm{~mm}$ & Memenuhi \\
V-funnel & $3.11 \mathrm{sec}$ & $2-5 \mathrm{sec}$ & Memenuhi \\
L-box & 0.94 & $0.8-1$ & Memenuhi \\
\hline
\end{tabular}

Nilai slump yang didapat pada pengujian beton normal adalah $11 \mathrm{~cm}$. Berdasarkan PBI 1971 nilai slump yang disyaratkan untuk beton normal adalah $7.5-15 \mathrm{~cm}$. Sehingga nilai slump memenuhi syarat.

\section{Hasil Pengujian Kuat Tekan}

Pengujian kuat desak silinder beton dilakukan menggunakan alat Universal Testing Machine (UTM) pada Laboratorium Material Teknik Mesin Universitas Sebelas Maret Surakarta untuk mengetahui kurva hubungan antara tegangan dan regangan beton yang terjadi saat pembebanan sampai mengalami keruntuhan. Hasil pengujian digunakan untuk membandingkan kurva tegangan-regangan beton pada beton HVFA-SCC dengan kadar fly ash $60 \%$ dan beton normal dengan menggunkan restraint teflon dan grease. Dengan beban maksimum dapat diperoleh kuat tekan beton dengan persamaan [1] berikut:

$f^{\prime} c=\frac{P}{A}$

keterangan :

$\mathrm{fc}=$ kuat tekan $\left(\mathrm{N} / \mathrm{mm}^{2}\right)$

$\mathrm{P}=\operatorname{beban}(\mathrm{N})$

$\mathrm{A}=$ luas penampang $\left(\mathrm{mm}^{2}\right)$

Tabel 5. Hasil Pengujian Kuat Tekan Beton Rata-Rata

\begin{tabular}{lccc}
\hline Benda Uji & Luas $\left(\mathbf{m m}^{2}\right)$ & $\begin{array}{c}\text { P Maks } \\
(\mathbf{N})\end{array}$ & $\begin{array}{c}\text { Kuat Desak } \\
\text { (MPa) }\end{array}$ \\
\hline HVFA.28.60 & 17671.46 & 417.74 & 23.639 \\
\hline NC28. & 17671.46 & 461.54 & 26.118 \\
\hline
\end{tabular}

\section{SIMPULAN}

Dari hasil pembahasan diatas dapat diambil kesimpulan sebagai berikut:

1. Dengan adanya subtitusi semen dengan fly ash sebesar $60 \%$ persyaratan beton segar Self Compacting Concrete (SCC) masih tetap terpenuhi.

2. Kuat tekan HVFA-SCC 60\% rata-rata masih lebih kecil dibandingkan dengan beton normal.

\section{REKOMENDASI}

a. Variasi umur HVFA-SCC yang diuji perlu dilakukan pada unur 56 hari dan 90 hari, karena diantara umur tersebut masih terjadi reaksi fly ash dilamnya sehingga hasil kuat tekan masih dapat mengingkat. 
b. Perlu dilakukan pembahasan lebih lanjut mengenai penggunaan restraint yang dapat mengurangi gaya friksi, untuk mengetahui perilaku murni dari beton tersebut tanpa dipengaruhi gaya friksi pada permukaan ujung spesimen dengan plat mesin uji.

\section{UCAPAN TERIMAKASIH}

Ucapan terimakasih penulis sampaikan kepada Bapak Agus Setiya Budi, S.T.,M.T. dan Bapak Prof. Stefanus Adi Kristiawan S.T., M.Sc., Ph.D. selaku pembimbing yang telah memberi bimbingan dan arahan sehingga penulis dapat menyusun penelitian ini dengan baik. Ucapan terima kasih juga penulis sampaikan untuk tim Gabungan Super selaku tim skripsi beton yang berjuang bersama-sama dalam menyelesaikan penelitian ini.

\section{REFERENSI}

Anonim. 2000. "SN1 03-2834-2002, “Tata Cara Pembuatan Rencana Campuran Beton Normal”. Badan Standarisasi Nasional, Jakarta

Anonim. 2002." Specification and Guidelines for Self - Compacting Concrete". EFNARC.

Anonim. 2013. "ACI Committe 374, "Guide for Testing Reinforced Concrete Structural Elements Under Slowly Applied Simulated Seismic Loads". American Concrete Institute, Farmington Hills.

Galang Nur Aji Pamungkas. 2017." Influence of Specimen Height to Diameter Ratio (b/d) on The Stress-Strain Response of High Volume Fly Ash Self Compacting Concrete under Uniaxial Compressive Loading". Universitas Sebelas Maret.

Karina Puspa Amalia. 2018 .’Pengaruh Kadar Fly Ash terhadap Karakteristik Material pada High Volume Fly Ash Self Compacting Concrete (HVFA-SCC)". Universitas Sebelas Maret.

S.Kumar, T. Mukhopadhyay, S.A. Waseem, B.Singh, M.A. Iqbal. 2016. "Effect of Platen Restrain on Stress-Strain Bahavior of Convrete Under Uniaxial Compression: A Comparative Study". Indian Institute of Technology Roorkee, Roorkee, India

Solikin, Mochamad. 2012. "High performance concrete with bigh volume ultra fine fly ash reinforced with basalt fibre". 